\title{
El eros y sus representaciones: del modernismo al posmodernismo
}

Palabras clave: poesía, erotismo, modernismo, posmodernismo, vanguardias

En este trabajo se analizan los aspectos de la concepción modernista del sexo y el erotismo que permanecen y evolucionan en el posmodernismo ${ }^{1}$ con el objetivo de observar si tales categorías son definitorias de una y otra corriente estética. Una primera aproximación a la obra poética de varios autores posmodernistas, entre los que se incluyen Baldomero Fernández Moreno, Ramón López Velarde y Regino E. Boti, conduce a la idea de que el erotismo como medio de comunicación con lo trascendente se diluye en esta poética y se erradica por completo en las vanguardias, como se muestra en la obra de Nicanor Parra. Una segunda aproximación nos lleva a percibir que el ideal de belleza modernista es suplantado por la fealdad - aunque no radicalmente. También se observa cómo el propio erotismo se instrumentaliza con fines diversos tales como la autoimposición del amor en el caso de la poesía lopezvelardiana. Para realizar este estudio comparativo es obligado tomar como parangón a la más destacada figura modernista, el poeta nicaragüense Rubén Darío. No obstante, también se considera la obra de otros modernistas, en especial la de aquellos en los que se vislumbra un punto de inflexión o evolución hacia una nueva estética, el posmodernismo, o que simplemente se establecen como contrapunto a la poesía meramente modernista o dariana.

$1 \quad$ El término posmodernismo es entendido en este trabajo tal y como lo desarrolla Hervé Le Corre en Poesía Hispanoamericana Posmodernista: «un discurso original, transnacional, transubjetivo» (2001: 15), conflictivo en sus prácticas literarias, integrador de elementos limítrofes, «sin renunciar tampoco a encontrar una dinámica común» (2001: 19), y que es, a su vez, binario, múltiple y disperso. En él se encuentran poetas «cuya obra esencial [...] no coincidió ni con el modernismo ni con las vanguardias, aunque pudo participar tangencialmente de ambas modalidades» (2001: 21). 
Previo al análisis y comparación de lo anteriormente expuesto es pertinente estudiar a las poetas incluidas en este ensayo como precursoras de lo que podríamos llamar un posmodernismo temprano o un modernismo contestatario en lo que al erotismo respecta. De este modo, resulta interesante cómo Alfonsina Storni y Delmira Agustini, incluidas dentro de la estética modernista dadas las características formales de su poesía, se alejan substancialmente de este canon en cuanto al contenido de sus versos y el tratamiento especial que le dan al erotismo, al igual que lo hace la posmodernista Gabriela Mistral. ${ }^{2}$

El erotismo en la estética modernista es clave como elemento configurador de una concepción binaria del mundo y el universo. Este concepto de tradición judeo-cristiana y neoplatonizante, ya presente en el romanticismo, propone una metafísica en torno al erotismo por la que el amor tiene la capacidad de crear y dar a conocer el orden del universo (Castillo, 1999: 117, 139). A su vez, el sentirse atraído por la mujer es una búsqueda epistemológica, un medio para separarse del mundo donde impera una crisis de valores, e intentar superar las propias incapacidades para entender el orden de las cosas. Para Rubén Darío la clave del conocimiento, la respuesta a lo que no se puede explicar, se obtiene mediante la relación erótica que no funcional entre el hombre y la mujer panerotismo-. Cathy L. Jrade afirma que:

Darío ha creado un mundo en el que el deseo físico se ha conciliado con el acorde universal y funciona como un medio para lograr la armonía universal [...] la exaltación de la mujer y del amor sexual funciona en tres planos semánticos simultáneamente - el cósmico, el personal y el poético- al tiempo que supone una fusión de lo espiritual con lo físico. (Jrade, 1986: 119-120)

El erotismo, por tanto, adquiere una gran importancia como puente de comunicación entre el mundo físico y el alma o realidad suprasensible, que es la verdadera realidad para estos poetas. También se asume como fuerza que mueve la tierra y explica la creación, como recurso contra el materialismo y el vacío espiritual producido por el positivismo y el naturalismo. ${ }^{3}$ Mediante

2 Hervé Le Corre (2001) incluye como posmodernistas a Delmira Agustini, Alfonsina Storni, Gabriela Mistral, Juana de Ibarbourou y María Eugenia Vaz Ferreira en cuanto a la nómina femenina. En cuanto a la masculina, recoge a los siguientes autores: Ramón López Velarde, Baldomero Fernández Moreno, José María Eguren, Porfirio Barba Jacob, Luis Carlos López, Regino E. Boti y Ricardo Güiraldes.

3 El erotismo se convierte para el poeta modernista en una de las armas de reacción contra positivismo prevaleciente a lo ancho y largo de América Latina durante el siglo XIX. 
la sexualidad se intenta volver a la unidad primitiva de la que el poeta se sabe separado. En palabras de Bataille (1997: 19): «somos seres discontinuos, individuos que mueren aisladamente en una aventura ininteligible; pero nos queda la nostalgia de la continuidad perdida», una discontinuidad que Darío logra subsanar momentáneamente mediante el acto sexual. Sexo y erotismo tienen de este modo un componente simbólico como manera de comunicarse con lo trascendente, con el universo. Esta visión sexual del universo proviene del pitagorismo esotérico en la que se basa la poesía dariana (Jrade, 1986:119). El cuerpo de la mujer permite, mediante el acto sexual, la comunicación con la naturaleza que es donde «el alma, por su origen y su destino, sólo encuentra su verdadera patria» (Raymond, 2002: 18). Para los modernistas, la mujer no es un fin en sí misma, sino una especie de símbolo cuya referencia es el mismo poema. Jrade señala a este respecto:

En el plano cósmico, humano y poético, la mujer guarda el secreto de la música y la armonía, del pulso ordenador de la vida y de los esquemas orgánicos y naturales del mundo [...] La poesía y la mujer celestial y mundana son la esencia de esa fuerza que habrá de permitir al hombre hacerse uno con el universo y alcanzar la unidad con lo que le rodea. (Jrade, 1986: 125)

No obstante, la belleza que la mujer suscita en el poeta es en ocasiones la misma que pudiera provocar la recepción estética de cualquier objeto decorativo. De este modo, Rubén Darío (1967: 36) en De invierno reduce a Carolina a un mero bibelot que como «un biombo de seda de Japón»o «jarras de porcelana china» se convierte en un elemento decorativo más de los que pueblan el espacio donde se encuentra. Esta belleza femenina en cuanto objeto es fácilmente profanada por el poeta modernista, quien mantiene encuentros sexuales y eróticos con la mujer sin hacer casi ninguna referencia al amor que pudiera sentir por ella. Esto se debe al miedo particular por el despliegue emocional, ya que éste podría perjudicar el dominio del verso, en consonancia con la ironía romántica. Esta casi inexistente mención al amor también será una constante en la poesía posmodernista.

En la obra de Darío son abundantes los poemas que hacen referencia al acto sexual, como se muestra en Mía: «Tu sexo confundiste / con mi sexo fuerte, / fundiendo dos bronces» (Darío, 1967: 569) o en Coloquio de los centauros: «Ah aroma de su sexo! Oh rosas y alabastros» (1967: 575). El erotismo también aparece en numerosos poemas como el ya mencionado De invierno o Carne celeste carne de mujer, donde esta carne celeste es la clave de conocimiento del 
universo (1967: 668-69), o también en Bouquet (1967: 564, 880) o en Era un aire suave, en el que Darío se expresa de la siguiente forma:

La marquesa Eulalia risas y desvíos

daba a un mismo tiempo para dos rivales

$[\ldots]$

cuando la bella su falda cogía

con dedos de ninfa bailando el minué. (Darío, 1967: 549-51)

Los anteriores son tan sólo algunos ejemplos en los que el nicaragüense recurre al erotismo y a la sexualidad y en los que toda manifestación de amor es desusada. ${ }^{4}$ La belleza sin la cual no se concibe a la mujer es mancillada por el poeta aunque no sin experimentar sentimiento de culpabilidad ante el instinto y la relación sexual. Ricardo Gullón señala a propósito de Rubén Darío:

Su sensualidad no era tan imperativa como para afirmarse contra todo y sobre todo. Al volcarse en la letra servía una finalidad purgativa, catártica, pero la servía relativamente, sin eliminar el deseo ni la sensación de culpa que lo acompañaba. $\mathrm{Su}$ angelismo no le impedía reconocerse -o reconocer otro yo suyo- en impulsos que pensó procedentes de la animalidad del cerdo con quien en alguna ocasión se identificó. (Gullón, 1967: $154-55$ )

Este sentimiento de culpabilidad que acompaña a Darío y a otros modernistas y también a algunos poetas posmodernistas es el reconocimiento no expreso de su concepción cosificante de la mujer. El poeta se siente culpable de inducir y conducir a la relación sexual a un "objeto no pensante" carente de voluntad, afianzándose así la reificación constante de la que es objeto el ente femenino en la poesía modernista.

\section{Eros femenino}

Las poetas "modernistas", entre las que señalo a Storni y Agustini, plantean una concepción distinta del erotismo bastante contestataria. La categorización de estas poetas como modernistas puede ser cuestionable, tal y como apunta

4 Cabe destacar que aunque no es muy común, se puede encontrar el amor en poemas como Sonatina donde el caballero: «llega de lejos, vencedor de la Muerte, /a encenderte los labios con un beso de amor!» (Darío, 1967: 557). 
Hervé Le Corre (2001: 23): «Delmira Agustini y Juana de Ibarbourou se relacionan más con el modernismo, pero lo reinterpretan personalísimamente». Este mismo autor recoge opiniones diferentes como la de Jean Franco, quien tilda a Agustini como "modernista tardío" o Giuseppe Bellini quien designa a Storni y Agustini como "posmodernistas". Como se aprecia, los lindes entre modernismo y posmodernismo no están perfectamente delimitados, y en lo que a las poetas respecta son mucho más difusos. Sobre Delmira Agustini y el erotismo Le Corre (2001: 243) señala: «A partir de ese dominio formal y temático de la textualidad modernista, o sea apoderándose de una técnica y de unos temas considerados tradicionalmente como masculinos, Delmira Agustini descompone el código erótico tradicional». Autores como Gwen Kirkpatrick, Sylvia Molloy, Tina Escaja, Delfinia Muschetti y Jorge Luis Castillo han apuntado que Agustini no sólo descompone el código erótico tradicional modernista, sino que incluso invierte sus símbolos destacando de especial manera cómo se apodera del cisne dariano en el poema Nocturno:

Engarzado en la noche el lago de tu alma,

diríase una tela de cristal y de calma

tramada por las grandes arañas del desvelo.

Nata de agua lustral en vaso de alabastros;

espejo de pureza que abrillantas los astros,

y reflejas la sima de la Vida en un cielo...

Yo soy el cisne errante de los sangrientos rastros,

voy manchando los lagos y remontando el vuelo. (Agustini, 2006: 254)

Es de sobra conocido el carácter emblemático del cisne dariano que opera de distintas formas tales como la poesía, la cultura, el hispanismo, el erotismo, la masculinidad, la interrogación y el cuestionamiento de la creación artística, entre otros. Sylvia Molloy (1985: 68) señala que en Nocturno «el cisne, y no un cisne, es destructor de armonía, violador de pureza, maculador: mancha (borronea, corrige) y escapa». Jorge Luis Castillo ha interpretado que en este poema:

El cisne sangrante asume las funciones que Delmira Agustini le asigna al poeta y éste deja su impronta, una mancha de sangre, 
sobre la página espejo en un gesto irreverente que altera el carácter platonizante de la estética modernista subvirtiendo el olímpico cisne de nieve, es decir, el principal Blasón de esta estética. (Castillo, 1998: 80)

Por tanto, Agustini feminiza el símbolo modernista por excelencia asociándolo a la sangre menstrual (y a la del parto) que, a su vez, remiten a lo prohibido, al sexo y a la violencias.

Este ,el cisne errante' ha luchado interiormente, ha experimentado la violencia interna, la prohibición que señala Bataille, y la ausencia de fecundidad, en este caso porque culmina en la menstruación. La poeta abandona, «remontando el vuelo», el espacio poético masculino, un espacio estéril, un espacio ajeno. Pese a este abandono, ha dejado su marca, la marca prohibida y violenta de la sangre menstrual. ${ }^{6}$

En la obra de Agustini se destaca no sólo la reapropiación contestataria del cisne dariano como símbolo fálico feminizado, sino también su manifestación como mujer sexualmente activa en igualdad con el varón. Se destruye así el principio de autoridad del hombre y se supera el papel pasivo y objetual que la estética modernista le asigna a la mujer. Como bien resume Tina Escaja (1989: 216), Agustini, «se muestra mucho más audaz en sus imágenes eróticas, al tiempo que multiplica la transgresión propia del modernismo mediante la intercambiabilidad de los roles tradicionales masculinos-femeninos y la incorporación del deseo sexual de la mujer».

Por su parte, Storni se rebela en su obra poética contra las convenciones sociales de su época y contra la dominación masculina. En Hombre pequeñito

5 Tal y como apunta Georges Bataille (1997: 58): «es el caso de la prohibición que cae sobre la sangre menstrual y sobre la sangre del parto. Estos líquidos son considerados manifestaciones de la violencia interna. Por sí misma la sangre es signo de violencia. El líquido menstrual tiene, además, el sentido de la actividad sexual y de la mancha que de ella proviene; esa suciedad es uno de los efectos de la violencia».

6 Escaja (1989: 221) señala en relación a este tema que «la revisión del mito modernista de Leda y el cisne, bosquejado en el poema ¡Oh, Tú!, se muestra particularmente transgresora en las imágenes sexuales empleadas por Delmira Agustini. La principal disidencia consiste en conferir poder y voz a Leda, con la que se identifica la hablante. El poder del yo lírico femenino permite entonces tanto la invención de un Dios alado (Zeus) con el que disfruta el intercambio sexual (a diferencia de la Leda engañada y violada por Zeus), así como la formulación poética de que la relación arquetípica es metáfora». En definitiva, señala Escaja (1989: 226), «si los escritores modernistas fragmentan sistemáticamente el cuerpo de la mujer tanto en los poemas como en la recepción crítica de las autoras, Delmira Agustini logra afirmarse en sí misma mediante el procedimiento de subvertir y revisar esas mismas metáforas». 
manifiesta abiertamente la opresión a la que la somete el hombre y su falta de entendimiento:

Estuve en tu jaula, hombre pequeñito,

hombre pequeñito que jaula me das.

Digo pequeñito porque no me entiendes,

ni me entenderás.

Tampoco te entiendo, pero mientras tanto,

ábreme la jaula, que quiero escapar;

hombre pequeñito, te amé media hora,

no me pidas más. (Storni, 1998: 26)

La voz poética no sólo denuncia la incomprensión que demuestra el hombre, sino que, en un acto que el pensamiento de la época censuraría, utiliza al hombre sexualmente por «media hora». Esta actitud feminista contra la mentalidad de la época se presenta también en Tú me quieres blanca en donde Storni (1998: 16) parodia la estética parnasiana tan utilizada por los modernistas en la que se destaca lo marmóreo, lo blanco y níveo, lo casto en definitiva. También se manifiesta en contra de la condenación masculina a la mujer que ha mantenido relaciones sexuales y la exigencia de virginidad como cualidad femenina. ${ }^{7}$

La mayoría de la crítica ha considerado a Mistral como una poeta posmodernista en cuya obra no se destaca una presencia marcada del erotismo. Dolores Koch en su artículo Delmira, Alfonsina, Juana y Gabriela señala a este respecto:

Una nueva expresión de erotismo caracteriza a estas tres voces femeninas: exaltado en Delmira, torturado en Alfonsina, sano y natural en Juana. De él se escapa Gabriela Mistral. Para ella, el amor es tema vital, pero lo sublima, lo universaliza. (Koch, 1985: 728)

7 Delfina Muschietti señala a este respecto que «la crisis del rol de la mujer constituye la materia central de la obra de Alfonsina. Sus textos y su acción cultural parecen tener la función de trasponer al nivel del campo intelectual y del sistema literario argentino la emergencia de este nuevo sujeto social» (Muschietti, 1989: 84). La crítica argentina sostiene que para Storni el «derroche de cisnes, tules, suspiros temblores, manos finas y delicadas tomados del pos-modernismo y el romanticismo tardío» son «palabra prestada» (1989: 86) y que «frente al discurso del estereotipo [...] se advierte desde las primeras obras de Alfonsina una esforzada actitud de contrapropuesta» (1989: 87). 
La propia crítica feminista ha visto con bastantes prejuicios la obra de Mistral representada como «la reina espiritual de toda la América Latina, el poeta de la maternidad de adopción, la gran cantadora de la misericordia y la maternidad» (Matthews, 1990: 57). En varios de sus poemas referentes a la maternidad, Mistral suprime la figura del amante, excluyendo lo masculino, para dar paso a la existencia de una comunidad en la que el sentido del matriarcado revela la idea de abundancia y unión entre mujeres. En Poema del bijo (Mistral, 1960: 94-97) - dedicado a Alfonsina Storni-y en Poemas de las madres en el que Mistral (1960: 151) dice: «pues en el que viene quiero amar a aquel que me besara», el hijo reemplaza o emula al amante. Encontramos por tanto en su poesía a un hijo erotizado y a un hombre desprovisto de todo protagonismo en el proceso reproductor y suplantado por una comunidad de mujeres o una suerte de comunidad femenina totalizadora. En estos versos queda superada la idea de "maternidad de adopción" sugerida por la crítica e incluso se pudiera interpretar la maternidad como algo compensatorio a la sexualidad frustrada y reprimida de la mujer tal y como la entiende el feminismo de la diferencia. ${ }^{8}$

Las poetas "modernistas", Agustini y Storni, y la posmodernista Gabriela Mistral presentan en su obra una visión bien distinta del erotismo al que desproveen de esa capacidad como vínculo epistemológico y de unión que tenía entre el poeta modernista y el universo, rompiéndose así la concepción binaria del mundo y el universo. También desaparece el vínculo modernista entre erotismo y belleza. En un estadio evolutivo toman el erotismo como elemento reivindicador y provocador en su lucha feminista, tal como hacen Storni y Agustini, y resaltan categorías vinculadas con éste, como la maternidad, que sólo pueden ser atribuibles a la mujer en el caso de Mistral. Este primer acercamiento al erotismo en la poesía de estas autoras confirma la hipótesis de que el erotismo ha dejado de ser un medio por el que el poeta intenta trascender su realidad inmediata para ponerse en contacto con la realidad supraterrenal de la que se sabe escindido.

\section{Eros masculino}

En la poesía de los autores modernistas Díaz Mirón, Lugones y Herrera y Reissig, vemos los primeros alejamientos de la idea que tiene Darío de la mujer

8 Esta idea es desarrollada en profundidad en el artículo de Irene Matthews (1990) Woman as Myth: The Case of Gabriela Mistral. 
y el erotismo. ${ }^{9}$ Muestra de ello es el poema La Giganta, de clara influencia baudeleriana, en el que Díaz Mirón se siente atraído y repelido por un "monstruo que me turba" (1901: 57), un monstruo que debido a sus dimensiones requiere dos sonetos para ser descrito. En A tus imperfecciones, Lugones insta a su amada a ser imperfecta "a despecho del canon adusto" (1974: 149). La representación femenina y el erotismo empiezan a tomar nuevos derroteros que culminan en poemas como La víbora ${ }^{10}$ de Nicanor Parra donde se concibe el erotismo y las relaciones sexuales como algo enajenante y desgastante. En un primer nivel, A tus imperfecciones parece estar dedicado a una mujer, pero a un nivel más profundo, esta silva parece estar dedicada a la propia poesía. Vemos en este poema de Lugones que no hay decoro, pero sí ironía y parodia. La belleza de la mujer es baudeleriana, no tiene ese contacto con lo divino. El autor argentino presenta una reflexión sobre la poesía en la que apuesta por reducir las expectativas del poeta y del propio arte poético. Ante la trascendencia vacua, ante lo inefable, se plantean dos posibilidades: abandonar la lira o redefinir el arte poético reduciendo las expectativas del creador y de la misma poesía. En este sentido, al reducir las expectativas, nos adentramos en el límite del modernismo. Lugones percibe estos límites y reflexiona sobre los cambios en la poesía. Es a través no sólo de un incipiente prosaísmo, sino a través de la mujer, desde donde advierte y reivindica los nuevos rumbos por los que va a dirigirse la lírica. ${ }^{11}$

En los versos de Regino Boti, Baldomero Fernández Moreno y Ramón López Velarde se advierte la evolución que va desde el concepto dariano de la mujer y el erotismo como medio de salvación hasta culminar en el extremo altamente negativo de la mujer-víbora de Nicanor Parra. En estos poetas se aprecia un aspecto disonante en la concepción modernista de la mujer y un gusto por explorar lo prosaico, en palabras de Octavio Paz (1974: 137): «ironía y prosaísmo» suponen «la conquista de lo cotidiano maravilloso». Para el gran crítico mexicano el fin de la alianza entre el sujeto y el universo se llama ironía (1974: 111). Mediante ésta el poeta se sabe separado de su entorno, es consciente de su caída, de estar lejos del orden universal. Además, la ironía, marca distintiva del poeta

9 Debe observarse que en el poema, $A$ Goya, el poeta nicaragüense define a la musa del pintor español de la siguiente manera: «Musa soberbia y confusa, / ángel, espectro, medusa. / Tal aparece tu musa» (Darío, 1967: 677). Se aprecia una definición de la mujer como entidad cambiante, hórrida y sagrada.

10 En el poema Serpentina, Delmira Agustini (2006: 294) se asume como serpiente: «En mis sueños de amor, ¡yo soy serpiente!»

11 Ramón López Velarde (1971) señala que «la idiosincrasia estática de los clásicos y la dinámica de los modernos [...] se intensifica de tal manera en Lugones, que llega a polarizarse». 
moderno, es clave tanto en los modernistas como en los posmodernistas, sobre todo en Nicanor Parra quien la lleva a sus máximas consecuencias.

En los poemas de Boti se perciben varias reminiscencias modernistas como las alusiones a lo marmóreo, lo cincelado, lo níveo y albo de la amada, características heredadas directamente de la estética parnasiana. Así, en varios poemas de Arabescos mentales, en la sección titulada Himnario erótico, encontramos recurrentemente adjetivos y nombres que hacen referencia al blanco, a la nieve, a la castidad y al nácar. Ejemplo de ellos son Nieve en campo de luz (Boti, 1913: 203), La ansiedad de mis pupilas (1913: 205), Connubio y visión en la alcoba (1913: 206) o Erosión nacarina (1913: 207). Esta constante la apreciamos también en Para tu piel sensual (1913: 208) y en Flor de virginidad donde la amada vuelve a ser esculpida esta vez por el «artífice inmortal» (1913: 215), por la mano de lo trascendente.

En este verso, «con que, en sueños contestabas a mi insinuación al Mal» (1913: 229), perteneciente a Ante el ara de tus formas, se aprecia que al igual que les ocurriera a los poetas modernistas, Boti experimenta cierta culpabilidad al sentir el deseo erótico y al incitar a la amada a la consumación del acto sexual. No obstante, la imagen de Boti se aleja de la amada inmaculada romántica, ya que en todos los poemas consuma el acto sexual e incluso tiene la experiencia de la maternidad como en Flor de virginidad. Por otro lado, se observa en el poeta cubano a una amada pasiva, objeto reificado, una mujer que incluso se ruboriza ante la contemplación de su propio sexo como ocurre en La ansiedad de mis pupilas donde el poeta se dirige directamente a una mujer que «en impensado movimiento, eludes / la visión de tu sexo en el encaje...» (1913: 205). En el único poema en el que apreciamos que la mujer toma cierto protagonismo en la relación sexual es en Pompones de carne (1913: 231) en donde sólo se alude al movimiento de sus caderas mientras mantienen la relación sexual. Aunque no se trata de ninguna iniciativa, y proviene de un «pompón de carne», al menos en esta ocasión la mujer adquiere movimiento propio, ya que en el resto de los poemas es meramente un objeto poseído e inmóvil.

La segunda estrofa de El acto parece invertir la concepción modernista que muestra a la amada como vínculo que permite al artista, al poeta, ponerse en contacto con lo trascendente:

Al perseguir la euritmia de su nuca

Para ofrendarle el culto de mi beso,

Mi espíritu de sátiro y artista

Quiso, para adorarla, ser eterno. (1995, 20) 
En este poema el poeta no ansía el contacto con lo eterno o la realidad supraterrenal, sino que es a la inversa: de esa esfera lo que le interesa es el contacto con la amada en un espacio intemporal, cuando para el modernista la mujer era la ayuda para alcanzar este mismo espacio.

Al igual que en la obra de Boti, en la de Fernández Moreno también aparecen reminiscencias parnasianas que hacen alusión a lo marmóreo, lo blanco y la nieve. De este modo, en el poema En la escalera de mármol, no sólo el título es alusivo, sino que en diferentes versos se aprecian estas referencias: «y era blanca, blanca, blanca /como las hostias y como los lirios» (Fernández Moreno, 1915: 69). En Mi romance a unas manos de nuevo encontramos alusiones a lo níveo, al marfil y a los lirios:

Manos que juegan en la falda azul;

nieve en el azabache de tu pelo,

lirios sobre las rosas de la cara,

marfil contra marfil, junto a tu cuello. (Fernández Moreno, 1915: 105)

Esta característica modernista no es la única que aparece en el poema. En la primera estrofa se nos presenta una amada que posee «...manos como dos milagros /de gracia, de blancura y misterio» (1915: 105). En este enigma de las manos de la amada, en este milagro, se puede observar una suerte de componente simbólico a la manera modernista que otorga a la mujer esa capacidad de comunicarse con lo oculto, con el universo, siendo por tanto sus manos un vínculo o un trasunto del misterio.

La concepción que Fernández Moreno tiene de la mujer es también bastante semejante a la de los poetas modernistas, ya que presenta un modelo convencional, arquetípico de finales del siglo XIX. Una mujer relegada al cronotopo femenino del hogar y de las labores domésticas relacionadas con la costura, la moda, la piedad religiosa, el cuidado de los hijos; una mujer desprovista de cualquier actividad intelectual y cuyo objetivo es el matrimonio (Litvak, 1979: 184-94). Para Fernández Moreno esta mujer posee unas manos que "bordan una flor o una inicial" o "saben consolar a los enfermos /acariciar a los niñitos pobres /y dar una limosna al pordiosero" (1915: 110).

Otra de las similitudes con la estética modernista de las que goza Fernández Moreno es la de experimentar ese sentimiento de culpabilidad que se desprende del deseo sexual, esa dualidad entre el deseo y la culpa que se manifiesta de esta forma en Lunes: «porque de todo estoy arrepentido.../ perdóname» (1915: 99). 
El exotismo, tan característico de la obra de Darío, «[quien] puebla su poesía de mujeres extranjeras en quienes busca lo raro, lo singular lo voluptuoso» (Litvak, 1979: 144) también está presente en la obra de Fernández Moreno como se observa en Roja inicial:

Yo te he soñado en esta larga noche,

toda desnuda en tu esplendor moreno

sobre el rojo damasco de mi cama.

Lacios, negros, opacos, tus cabellos

en alisados mechones, descendían

hasta el heroico cisma de tus senos. (cit. por César Fernández Moreno, 1956: 71)

Como en el caso de Lugones o Díaz Mirón, Fernández Moreno presenta un punto de inflexión con respecto a las características con las que Darío representa a la mujer. Al describir la belleza de la amada, el poeta destaca una de sus imperfecciones y le dedica toda una estrofa «al más deforme de sus pequeñuelos», a ese dedo «con la cicatriz» que «está muy feo» (Fernández Moreno, 1915: 109). Se distancia por tanto de la absoluta belleza de la que goza en la poesía dariana y nos presenta una mujer que ya no es absolutamente la «carne celeste» que permite el conocimiento metafísico. ${ }^{12}$ Esta visión de la «carne celeste» es mancillada por Fernández Moreno en El amor de antes, la compasión de abora donde compara a la mujer con una baldosa de la calle que al pisarla «te salpican y te ensucian /el traje limpio de manchas de barro» $(1915: 32)$. En Inicial heroica esta carne de tintes celestiales para Darío es totalmente profanada, ultrajada y devorada de forma violenta: ${ }^{13}$

12 En el poema, ${ }_{i}$ Carne celeste, carne de mujer!, tal y como destaca Cathy L. Jrade, Darío expresa la relación que él establece entre realidad terrenal y suprasensible a través de la mujer: «En este poema, a través de la fusión de lo cósmico y lo concreto, la mujer de carne y hueso se espiritualiza como la imagen terrena de la divinidad femenina y la existencia del espíritu femenino de la divinidad se hace más patente por medio de su descripción física y sexual. Más aún, la perfección armoniosa de la mujer cósmica y concreta y su promesa de unidad ideal se capturan en la carne del lenguaje, inseminado por la 'música ideal' del poeta» (Jrade, 1986: 123).

13 Nótese la reminiscencia de este verso con el poema de Baudelaire Una carroña y con el poema Idilio de Díaz Mirón. 
Ven, castellana; gozaré tu amor

y te daré después a mis guerreros,

y cuando todos se harten de tu carne,

en la almena más alta te comerán los cuervos. (Fernández Moreno, 1915: 83)

Otro aspecto que separa la poesía de Fernández Moreno de la poesía modernista es la explícita expresión de sus sentimientos, aspecto que no observamos en la poesía de Rubén Darío. Así, en Mi romance a unas manos el poeta queda preso de la amada:

mi pobre corazón, mi dolorido

y triste corazón, se queda preso

¡tal como un pajarito tembloroso

en la jaula de lirios de tus dedos. (Fernández Moreno, 1915: 105)

Además de proclamar su amor, otra de las constantes en la poesía de Fernández Moreno es su continua alusión al fracaso amoroso tal y como lo manifiesta en El amor de antes, la compasión de abora donde «tu traición me dejó dolorido y asqueado» (1915:32) o en Breve elegía en los funerales de un breve amor donde se funden mujer y dolor: «ya pasó por mi vida otro dolor /ya pasó otra mujer» (1915: 129).

La poesía de Fernández Moreno tiene una clara deuda con la estética modernista, de la que se destacan su concepción reificante de la mujer, sus reminiscencias parnasianas en alusión a lo níveo, blanco o marmóreo, la expresión del sentimiento de culpa al sentir el impulso y el deseo sexual y la presencia de elementos exóticos. Al mismo tiempo, incluir elementos de la fealdad para describir a la amada, profanar y mancillar su carne apunta hacia una parodia de la obra de su deudor. De este modo, la parodia permite al poeta dialogar con el discurso modernista desde el ejercicio poético y, al aunar estas dos posiciones, rendir tributo a Rubén Darío al mismo tiempo que parodia su estética, se puede decir que la obra de Fernández Moreno además de ser posmodernista posee rasgos que comparten características con el postmodernismo. ${ }^{14}$

En cuanto a Ramón López Velarde, el poeta mexicano instrumentaliza el amor en su obra, ya que sacrifica su historia amorosa en aras de un estatus social elevado. Gabriel Zaid propone una visión trovadoresca del amor de López Velarde por Josefa de los Ríos, Fuensanta, en sus poemas. Pero este trovador 14 Véase A poetics of postmodernism: bistory, theory, fiction de Linda Hutcheon (1988: 35). 
posmodernista «sacrifica a la pareja del amor posible, porque aspira a más» (Zaid, 1986: 8). En el poema No me condenes... pide perdón explícitamente a su amada en el momento de abandonarla, ya que no ostenta la posición social y económica deseada por el poeta:

Yo tuve, en tierra adentro, una novia muy pobre:

ojos inusitados de sulfato de cobre.

llamábase María; vivía en un suburbio,

y no hubo entre nosotros ni sombra de disturbio.

acabamos de golpe: su domicilio estaba

contiguo a la estación de los ferrocarriles,

y ¿̨qué noviazgo puede ser duradero entre

campanadas centrífugas y silbatos febriles?

[...]

¡Perdón, María! Novia triste, no me condenes (López Velarde, 1971: 140) El poeta rompe su relación con María, «una novia muy pobre» que «vivía en un suburbio», por el mero hecho de que ella carece de recursos, ya que no se presentan otros elementos que pudieran haber influido en su decisión de terminar con el noviazgo salvo el hecho de que ella no goce de un buen estatus económico. Lo imposible en el amor de este trovador ya no es social sino autoimpuesto, no es algo externo lo que impide a López Velarde la plena realización del yo en la pareja, sino que es la pareja en sí misma la que impide la realización del yo. El poeta rechaza un amor ya alcanzado en pos de un mejor posicionamiento social que le hubiera sido mermado de haber permanecido junto a Fuensanta. Zaid (1986: 16) señala que nada impedía la realización de la pareja salvo la ambición de López Velarde: «la pobre María lo es como parte mutilada de una pareja posible, como la parte que se queda, en vez de ir a su plenitud. Nada externo impedía la pareja, sino las ambiciones del joven provinciano». ${ }^{15}$

Si el erotismo y la representación de la mujer suponen un cambio paradigmático para los poetas situados entre las fronteras del modernismo y las vanguardias, la concepción de la mujer a la manera de Darío se desvanece por completo en la poesía del vanguardista chileno Nicanor Parra. En su

15 Zaid (1986; 15-16) argumenta que en realidad López Velarde invierte el mito trovadoresco y la propia realidad, ya que según muestra este autor, María gozaba de mejor situación económica que el poeta. 
poema La víbora presenta una visión misógina de la mujer y una actitud negativa sobre el amor y el sexo. ${ }^{16}$ El apelativo con el que el poeta nomina a la mujer, víbora, es suficientemente descriptivo. Además de las connotaciones de esta palabra alusivas a una persona mordaz, murmuradora, maldiciente y con malas intenciones, existen otras de gran valor connotativo tal como señala Lily Litvak:

Según Jung, encarna lo inconsciente, lo que puede elevarse contra nosotros en nosotros mismos. Según Alain, la serpiente es indudablemente un símbolo fálico y representa al hombre a la proa de sus deseos y sus pasiones. En la interpretación psicoanalítica de este símbolo, algunos lo reducen a la proyección psicológica del deseo, a la manifestación de la naturaleza animal del hombre, semiahogada por prohibiciones morales y sociales. (Litvak, 1979: 43)

Debe considerarse la referencia bíblica a este animal que seduce y arrastra a la tentación y al pecado y observar que Parra hace alusión a Eva, tentada por la serpiente: «Entonces pude percatarme de que ella se presentaba ahora provista de un pequeño taparrabos» (Parra, 1971: 150). La víbora-mujer en Parra posee gran parte de los elementos anteriormente mencionados. Por un lado, es un ser que despierta en el poeta una tentación erótica que lo fascina: «so pena de caer en descrédito antes sus ojos fascinantes» (1971: 145) hasta el punto de «realizar pequeños robos» (1971: 145) y «llevar a cabo algunos delitos» (1971: 145). La víbora-mujer lo tiene preso en una relación basada en el sexo y en la explotación económica:

Largos años viví prisionero del encanto de aquella mujer

Que solía presentarse a mi oficina completamente desnuda

Ejecutando las contorsiones más difíciles de imaginar

Con el propósito de incorporar mi pobre alma a su órbita

Y, sobre todo, para extorsionarme hasta el último centavo. (Parra, 1971: 146)

La explotación económica a la que es sometido el poeta es tal que al final del poema se invierten los términos y tiene que depender de la caridad de la amante para sobrevivir:

16 Karen S. Van Hoof (1982) hace un extenso análisis de este poema en su artículo «Vipers, Victims, and Virgins: Women and Relationships with Men in the Poetry of Nicanor Parra». 
Tráeme un poco de agua, mujer,

Consígueme algo de comer en alguna parte,

Estoy muerto de hambre,

No puedo trabajar más para ti,

Todo ha terminado entre nosotros. (Parra, 1971: 151)

La mujer se ha convertido, por tanto, en un ser activo en materia sexual e intelectual: «ya he terminado mis estudios, me he recibido de abogado» (1971: 150), extorsionadora y manipuladora. De la mujer vínculo con el más allá de Darío no queda ni siquiera un mínimo vestigio comprobándose que desde la «carne celeste» hasta la «víbora», la representación de la mujer, del sexo y el erotismo evolucionan y se subvierten hasta un punto en que se permite afirmar que estas categorías son definitorias de las corrientes modernista y posmodernista. La mujer, su aproximación y concepto, sirve a los poetas del último modernismo (Lugones y Díaz Mirón) y a los poetas posmodernistas como un elemento de crítica y reformulación de una corriente poética que toca su fin, «del canon adusto», aunque no se puede afirmar que toda la poesía posmodernista sea meramente «una práctica de restas, sino también de sumas» (Castillo ${ }^{17}$ ), ya que los débitos con el modernismo aún se aprecian claramente.

Desde la concepción binaria del mundo y el universo, en la que el erotismo es clave como elemento configurador de la misma, se evoluciona hasta un extremo en el que ya no se puede hablar de un sistema binario sino de un "sistema crítico" (Parra, 1971: 478) como lo define López Velarde junto a Guillermo Sucre (1975) y Hervé Le Corre (2001), quienes apuntan además a la multiplicidad y dispersión del mismo. Todo ello sin pasar por alto el marcado sesgo de género que el tratamiento del erotismo tiene tanto en las poetas posmodernistas como "modernistas" para quienes el erotismo es una de las claves importantes como elemento de crítica y revisión al canon patriarcal imperante que supuso el modernismo. El sexo y el erotismo son, por tanto, elementos definitorios y diferenciadores de una y otra corriente estética, y se significan como un punto de inflexión fundamental en el cambio del modernismo al posmodernismo.

17 De este modo fue definida por Jorge Luis Castillo en un seminario sobre poesía posmodernista impartido en la Universidad de California en Santa Bárbara en el año 2002. 


\section{Bibliografía}

Agustini, D. (2006): Poesías completas. Madrid: Cátedra.

Astrada de Terzaga, E. (1967): «Figura y significación de Alfonsina Storni».

En: Cuadernos Hispanoamericanos, 211, 124-44.

Bataille, G. (1997): El erotismo. México: Tusquets.

Boti, R. (1913): Arabescos mentales. Barcelona: Tobella.

Castillo, J L. (1998): «Delmira Agustini o el modernismo subversivo». En: Chasqui, 28.2, 70-84.

Castillo, J L. (1999): El lenguaje y la poesía de Julio Herrera y Reissig. Montevideo: Biblioteca de Marcha: Dirección General de Asuntos Culturales: Ministerio de Relaciones Exteriores.

Darío, R. (1967): Poesías completas. Madrid: Aguilar.

Escaja, T. (1989): «(Auto)Creación y revisionismo en Los cálices vacíos de Delmira Agustini». En: Bulletin of Hispanic Studies, 75.2, 213 - 28.

Fernández Moreno, B. (1915): Las iniciales del misal . Buenos Aires: José Tragant.

Fernández Moreno, C. (1956): Introducción a Fernández Moreno. Buenos Aires: Emece.

Gullón, R. (1967): «Rubén Darío y el erotismo». En: Papeles de Son Armadans, $4.136-138,143-58$.

Horan, E R. (1990): «Matrilineage, Matrilanguage: Gabriela Mistral's Intimate Audience of Women». En: Revista Canadiense de Estudios Hispánicos, 14.3, 447-57.

Hutcheon, L. (1988): A poetics of postmodernism: bistory, theory, fiction. New York: Routledge.

Jrade, C. (1986): Rubén Darío y la búsqueda de la unidad. El recurso modernista a la tradición esotérica. México: Fondo de Cultura Económica.

Kirkpatrick, G. (1989): «The Limits of Modernismo: Delmira Agustini and Julio Herrera y Reissig». En: Romance Quarterly, 36.3, 307-14.

Koch, D. (1985): «Delmira, Alfonsina, Juana y Gabriela». En: Revista iberoamericana, 1.132-133, 723-729.

Le Corre, H. (2001): Poesía Hispanoamericana Posmodernista: bistoria, teoría, prácticas. Madrid: Gredos.

Litvak, L. (1979): Erotismo fin de siglo. Barcelona: A. Bosch.

López Velarde, R. (1971): Obras. México: Fondo de Cultura Económica. 
Lugones, L. (1974): Obras poéticas completas. Madrid: Aguilar.

Matthews, I. (1990): «Woman as Myth: The 'Case' of Gabriela Mistral». En: Bulletin of Hispanic Studies, 57, 57-69.

Mistral, G. (1960): Desolación. Buenos Aires: Espasa Calpe.

Molloy, S. (1985): «Dos lecturas del cisne: Rubén Darío y Delmira Agustini». En: Patricia Elena González, Eliana Ortega (eds.), La sartén por el mango: encuentro de escritoras latinoamericanas. Río Piedras: Huracán, 57-69.

Muschietti, D. (1989): «Las mujeres que escriben: aquel reino anhelado, el reino del amor». En: Nuevo texto crítico, 4.2, 79-102.

Parra, N. (1971): Poemas y antipoemas. Santiago de Chile: Nascimento.

Paz, O. (1974): Los bijos del limo. Del romanticismo a la vanguardia. Barcelona: Seix Barral.

Percas de Monseti, H. (1982). «Reflexiones sobre la poesía femenina hispanoamericana». En: Revista Review latinoamericana, 12.1, 49-55.

Raymond, M. (2002): De Baudelaire al surrealismo. México: Fondo de Cultura Económica.

Sucre, G. (1975): La máscara, la transparencia. Caracas: Monte Ávila.

Storni, A. (1998): Selección poética. Kassel: Reichenberger.

Van Hooft, KS. (1982): «Vipers, Victims, and Virgins: Women and their relationships with men in the poetry of Nicanor Parra». En: Gabriela Mora y Karen S. Van Hooft (eds.), Theory and Practice of Feminist Literary Criticism. Ypsilanti: Bilingual, 56-78.

Varas, P. (1994): «Lo erótico y la liberación del ser femenino en la poesía de Delmira Agustini». En: Hispanic Journal, 15.1, 165-84.

Zaid, G. (1986): «Un amor imposible de López Velarde». En: Vuelta, 9.110, 7-17. 


\author{
Alicia Rita Rueda-Acedo \\ University of Texas at Arlington
}

\title{
Representations of Eros: From Modernismo to Posmodernismo
}

Keywords: poetry, eroticism, modernism, postmodernism, vanguards

In this paper I explore eroticism as a key element in the evolution from modernismo to posmodernismo. If eroticism is a crucial component to understand the binary concept of the world and the universe present in modernist poetry, postmodernist poets distance themselves from this outlook towards a "critic system". In order to explore this shift, I analyze the works of postmodernist poets such as Baldomero Fernández Moreno, Ramón López Velarde and Regino E. Boti, and vanguardist poet Nicanor Parra, comparing their writing to Rubén Darío's. I emphasize the evolution from Darío's conception of the universe where women play an integral role to Parra's conception of the woman as a viper and how this change is related to a substantial change of the conception of poetry. I also study eroticism in the work of Alfonsina Storni, Delmira Agustini and Gabriela Mistral as an instrument to critic and review the patriarchal cannon imposed by modernism. These poets eliminate the connection between eroticism and beauty, and they claim eroticism as a differentiating tool in their feminist writing and agenda. Sex and eroticism are elements that define and differentiate modernism from postmodernism, and can be considered as a crucial turning point for this shift. 


\author{
Alicia Rita Rueda-Acedo \\ University of Texas at Arlington
}

\title{
Eros na poti od modernizma do postmodernizma
}

Ključne besede: poezija, erotizem, modernizem, postmodernizem, avantgarde

Prispevek raziskuje erotiko kot bistven dejavnik v razvoju od modernizma do postmodernizma. Če je erotika ključnega pomena za razumevanje binarnega pojmovanja sveta in univerzuma $\mathrm{v}$ modernistični poeziji, se postmoderni pesniki oddaljijo od tega koncepta in se usmerijo v »kritični sistem«. Da bi raziskala to preobrazbo, avtorica prispevka analizira pesniška dela postmodernistov, kot so Baldomero Fernández Moreno, Ramón López Velarde in Regino E. Boti, in avantgardista Nicanorja Parre ter jih primerja z deli modernista Rubéna Daría. Prav tako se posveča analizi erotike v delih pesnic Alfonsine Storni, Delmire Agustini in Gabriele Mistral kot osnove za kritiko in revizijo patriarhalnega kanona, ki ga je uveljavil modernizem. V delih omenjenih avtoric izgine vez med erotiko in lepoto. Erotika postane sredstvo v boju za pravice žensk. Spolnost in erotika opredeljujeta ter ločujeta modernizem od postmodernizma, zato veljata za ključna elementa pri prehodu iz modernizma $\mathrm{v}$ postmodernizem. 